\title{
O CORPO EM MÚLTIPLAS CENAS
}

\author{
EL CUERPO EN MÚLTIPLES ESCENAS
}

\section{THE BODY IN MULTIPLE SCENES}

\author{
Eduardo Tessari Coutinho ${ }^{1}$
}

\begin{abstract}
RESUMO
Neste texto-ensaio procuro fazer uma breve reflexão inspirada no tema proposto para esta revista: poéticas do corpo em cena. Um depoimento do meu caminho na arte, na pesquisa - técnica, dramaturgia, linguagem - e na docência, entremeado com reflexões. As atividades de artista, de pesquisador e de professor são contaminadas, friccionadas num mesmo corpo.

PALAVRAS-CHAVE: ator, consciência corporal, mímica, pesquisa prática em arte, teatro popular.
\end{abstract}

\section{RESUMEN}

En este texto-ensayo procuro hacer una breve reflexión inspirada en el tema propuesto para esta revista: poéticas del cuerpo en escena. Un relato de mi camino en el arte, de mi investigación - técnica, dramaturgia, lenguaje - y de la docencia, entremezclado con reflexiones. Las actividades de artista, de investigador y de profesor se contaminan y se rozan en un mismo cuerpo.

Palabras clave: actor, conciencia corporal, mímica, investigación práctica en arte, teatro popular.

\section{ABSTRACT}

This essay is a brief reflection inspired by this magazine proposed theme: body's poetics in scene. A testimony of my path in art, research technique, dramaturgy, aesthetics- and teaching, permeated with reflections about it. The activities as artist, researcher and teacher are contaminated, rubbed in the same body.

KEYWORDS: actor, body awareness, mime, practical research in art, popular theatre

\author{
$* * *$ \\ Fazer mímica é-para o ator, para a escrita e para \\ a interpretação - um ato fundamental, o ato \\ primeiro da criação dramática. \\ (Jacques Lecoq)
}

\footnotetext{
1 Ator-mímico, Professor Doutor no Departamento de Artes Cênicas e no Programa de PósGraduação em Artes Cênicas da ECA-USP, coordenador do grupo de pesquisa CEPECA, edumimo@usp.br
} 
O processo de reflexão sobre uma pesquisa consiste, por vezes, em revisitar o seu percurso como pesquisador. E este é o meu atual momento. Ao ler as possibilidades de temas para esta revista me remeteram a algumas inquietações minhas: como é este corpo que está na cena, mas que também está na sala de aula e na pesquisa (teórica e prática)? Como a mesma pessoa transita e percebe a contaminação entre esses papéis distintos neste mesmo corpo?

O meu início como ator-mímico² foi no final dos anos 70 , do século passado, na rua e com mímica. E a mímica silenciosa! O risco era para além do estar na rua, era também da repressão da ditadura militar. As apresentações ocorriam na praça, na passeata, mas também em festas e shows estudantis, tanto em palco quanto fora dele, quase sempre com caráter político. A vivência de estar em cena com a consciência, àquela altura, de poucos instrumentos técnicos me levou a estar atento em cena a características que todos nós humanos temos, a observação, a escuta, e a percepção disponível para captar o momento, o espaço, o contexto, os sentimentos...

E vinham os meus sentimentos de medo e coragem, as minhas sensações de estar perdido, de estar poderoso... Mas a certeza de ser parte de um movimento coletivo, de luta política, social, é que gerava uma alegria densa, profunda, mesmo em tempos difíceis. E agora, após 36 anos de artista e com quase 29 anos de estar professor, pesquisador e, mais recentemente, como orientador de pós-graduação nas áreas da mímica, da consciência do corpo, do artista popular, da dramaturgia do corpo em cena, que resposta eu tenho para aquelas perguntas?

Vamos por partes.

Minha pesquisa é pautada por três pilares: a linguagem popular (Henryk Tomaszewski e Carlos Alberto Soffredini), a consciência de corpo (Balé - variados gêneros, Gerda Alexander e Klaus Vianna) e, mais recentemente de forma organizada, a visão da relação de grupos (Jacob Levy

2 Uso aqui "ator-mímico" por constar assim o meu registro profissional na carteira de trabalho. 
Moreno). Estes conteúdos aparecem ao mesmo tempo como base teórica e para dar conta de uma prática. E se entretecem.

Tudo começou com a mímica de Tomaszewski, mestre de meu primeiro professor, que possibilitou criar esquetes no formato predominantemente fora do edifício teatral e em contexto de luta política coletiva. Foi a fase do aprender fazendo. Eu organizava a experiência da cena pela necessidade de algo que pudesse ser refeito, de estar aperfeiçoando. Naquele período eu apresentava esquetes de mímica, estudava balé, como trabalho corporal organizado, e cursava engenharia civil na Escola de Engenharia de São Carlos - USP. Havia poucos interlocutores da linguagem teatral e nenhum especificamente de mímica.

Quando terminei a faculdade e assumi ser um mimo ${ }^{3}$, viajei a Paris, França, para me aprofundar na mímica de Tomaszewski no Studio Magenia, além de alguns cursos curtos. Na volta a São Paulo houve o encontro com Carlos Alberto Soffredini e seu grupo teatral ESTEP, que pesquisava na prática uma estética teatral popular e o seu respectivo ator. Soffredini, falecido em 2001, era um artista-pesquisador, não acadêmico, mas que lia, fazia pesquisa de campo, experimentava para escrever e dirigir suas peças. Ele ganhou uma bolsa Fulbright para escrever um melodrama brasileiro, que resultou na escrita da peça De Onde Vem o Verão. Também me ajudou a perceber o que eu já sabia, me dando consciência do conhecimento que havia adquirido na minha prática. No ESTEP eu dirigia os atores na parte corporal. Nunca coreografei, sempre construí os movimentos com e a partir do corpo dos atores. Lá também aplicava a linguagem do ator popular, o ator de rua, como a triangulação, o solilóquio, e o uso da ilusão em um teatro com pouco cenário e adereços de cena.

Também conheci nesta época, na área do corpo, a Eutonia, de Gerda Alexander, em aulas e estudos. Mas o principal mestre eu encontrei logo em seguida, Klaus Vianna, com quem tive aula e contato por alguns anos. Ambos, Gerda e Klaus, eram pesquisadores não acadêmicos com grande reconhecimento por seus estudos corporais.

\footnotetext{
${ }^{3}$ Usarei sempre o termo mimo neste texto para designar a artista da cena (ator, performer etc.) 
Foi neste momento que iniciei a minha pesquisa acadêmica.

A partir do trabalho de consciência do corpo de Klaus eu organizei os princípios técnicos da mímica, trazendo o viés da consciência do corpo para o processo de repetição. E, a partir dos estudos de linguagem popular de Soffredini, eu desenvolvi a minha poética como mimo. Considero a mímica como parte do veio popular do teatro, por uma questão histórica ${ }^{4}$.

A partir destas duas linhas de influência iniciei o estudo de uma dramaturgia conduzida pelo corpo, tendo como base a minha experiência como ator-mímico.

$\mathrm{Na}$ pós-graduação em artes cênicas conheci o psicodrama (ou sociodrama) em aulas com Clóvis Garcia, que seria meu futuro orientador, e nunca mais parei de ler sobre este tema. O pensamento da constituição do ser humano a partir das relações, da inclusão, o olhar de grupo, o interpsíquico no processo de autoconhecimento, da inclusão do corpo no processo terapêutico, como propõe $\mathrm{Moreno}^{5}$, contaminou o meu pensamento sobre como estar no mundo.

A mímica para mim não é uma arte separada do teatro. $\mathrm{O}$ próprio Etienne Decroux ${ }^{6}$ dizia que o teatro é a arte de ator. Burnier explica: "Ele se refere a uma arte que emana do ator, algo que lhe é ontológico, próprio de sua pessoa-artista, do 'ser ator'. E não à arte do ator, pois ela não lhe pertence, ele não é seu dono, mas é quem a concebe e realiza" (BURNIER, 2009, p.18). A mímica não se restringe ao falar ou não em cena. O mimo grego e o romano falavam: "Entre os gregos e os romanos, entretanto, mimar significava usar o corpo e a voz, vestir máscaras, saltar com pernas de pau, realizar jogos acrobáticos, atuar dançando e cantando...” (FO, 2004, p.268). Mas em alguns momentos históricos os mimos foram privados da fala, principalmente por motivos políticos.

Portanto, o foco da mímica, até por ser uma arte de rua, é ter a dramaturgia no corpo e na relação. Esta dramaturgia pode contar uma fábula, com certa coerência de espaço/tempo, o que eu denomino como

\footnotetext{
${ }^{4}$ Ver na minha dissertação, que consta das Referências, "Um Breve Histórico da mímica".

5 Jacob Levy Moreno, criador do Psicodrama.

${ }^{6}$ Principal mestre de mímica do século XX.
} 
pantomima. Ou pode ser uma dramaturgia simbólica, aproximando-se da poética da dança. Entre estes extremos, cada artista escolhe a sua poética. "O objeto do mimo é vasto, abrangente; do ponto de vista humano, ilimitado. Isto é o que diz a palavra grega pantomimos, "aquele que mima tudo»" (REY, 1987, p.12).

As técnicas mais conhecidas da mímica, em especial a do Tomaszewski, são aquelas que nos fazem ter a ilusão de um objeto inexistente. Eu chamo de técnicas ilusórias a "parede", o "ponto fixo", o "andar sem sair do lugar", dentre outras. Elas cumprem uma importante função de facilitar a vida do mimo de rua, permitindo que ele não precise ter muito espaço para se apresentar, nem muitas coisas para carregar, além de poder criar diferentes coisas não previstas na cena improvisada. Mas a mímica é mais do que uma ação descritiva, ela é potente também ao colocar em cena a subjetividade humana. Além disso, mesmo a ação descritiva é definida pelo subjetivo. Ao se fazer uma parede, por exemplo, há uma ação técnica descritiva, mas se esta parede impede a fuga ou é uma proteção, o modo de fazer dará necessariamente um resultado cênico diferente.

Outra importante característica da arte da mímica é a que o público constrói na imaginação tudo o que é criado pelo mimo em cena, sem tirar os olhos do corpo dele.

J'imitais le visage, les gestes et parler des interlecuteurs et l'on eût cru que plusieurs s'exprimaient par une seule bouche... Ainsi le funèbre jour a ravi avec moi tous les personnages qui vivaient em mon corps. ${ }^{7}$ (Epitáfio do mimo Vitalis, em torno do séc. IX)

"O mimo identifica-se, ele mesmo, com o objeto, suas características e proporções" (COUTINHO, 1993, p.47).Daí decorre a minha leitura da pedagogia da mímica de Tomaszewski. Ele propõe que o corpo em cena espelhe tudo e todos com que ele se relaciona. Isto é, o corpo está sempre em relação e, como um espelho, o mimo desvela pelo seu corpo tudo com o que ele está se relacionando. E minha observação comprova isso. Os corpos são contaminados na relação e revelam tudo, como, por exemplo, o espaço e os

\footnotetext{
${ }^{7}$ Eu imitei o rosto, os gestos e a fala dos personagens e fiz crer que muitos se manifestaram por uma só boca... Assim o fúnebre dia arranca de mim todos os personagens que viveram no meu corpo (livre tradução).
} 
objetos (dados objetivos), assim como a percepção e os sentimentos (dados subjetivos).

O corpo como espelho é um princípio de Tomaszewski. Por exemplo, ao se relacionar com uma pessoa alta, o corpo se curva como um espelho convexo no sentido vertical. Ao se relacionar com alguém muito baixo, ele se curva como um espelho côncavo no sentido vertical. Assim também com objetos: para um poste, um corpo convexo na vertical; mas para uma parede alta e larga, um corpo convexo na vertical e também na horizontal.

Outro princípio é a relação do uso das articulações do corpo com os objetos. Por exemplo, ao seguramos um copo de plástico sem valor ou se é uma taça de cristal cara, em cada situação destas descritas, o corpo se move de maneira distinta em função da importância que se dá ao objeto. Ao segurarmos o copo de plástico, as articulações do pulso, do braço e do resto do corpo podem se mover soltos. Mas quando damos importância ao objeto, a taça de cristal cara, movemos usando as articulações mais distantes e restringindo o movimento das mais próximas da mão (onde está o objeto imaginário). Portanto, quanto mais importante, mais articulações ficam com o movimento contido (pulso, cotovelo, ombro, coluna...). Esta estrutura corporal se repete se seguramos um copo cheio de água até o limite (mais articulações contidas) ou com apenas um pouco de água (mais articulações livres); ou se estamos segurando uma agulha com veneno na ponta ou não etc.

Outro uso das articulações é na relação com o tamanho dos objetos. Quanto maior o objeto, mais articulações estão envolvidas. Exemplos: ao abrir uma tampa de um frasco de remédio, usam-se apenas os dedos para girar. Uma tampa maior, move-se também o pulso; uma direção de carro, acrescenta-se o cotovelo e a cintura escapular; uma direção de ônibus, também envolve a coluna; e, por fim, uma trava de cofre de 1,5 metros girase usando todo o corpo. Este também é o princípio quando pensamos no uso da força. Quanto mais força, mais articulações estão envolvidas no movimento. Quando assistimos um profissional apertando um parafuso de 
roda, ele inicia girando com as mãos a chave de roda e, ao final, usa todo o corpo para apertar bem o parafuso.

Ainda sobre os dados objetivos, temos o princípio do contraponto para criar o espaço. Pelo princípio da identificação, quando um foguete sobe, por exemplo, quem está observando no local tende a acompanhar a subida com os olhos subindo, depois com o pescoço, depois o peito e, quando começa a ficar muito longe, tendemos a abaixar o corpo, buscando olhar o objeto que agora está muito pequeno no céu. Outro exemplo é a despedida de alguém. No início tendemos a inclinar o corpo um pouco na direção da pessoa que se distancia para dar tchau, como se fossemos tocar com as mãos. Quando ela fica longe, tendemos dar um passo para trás e levantar mais a mão com o tchau. Portanto, ao movimentar o corpo no sentido oposto, amplia-se o espaço entre mim e a pessoa ou objeto que se distancia. Esta técnica também é usada para puxar uma corda comprida.

Há também a identificação com o material, isto é, se é madeira, cimento, metal etc. Uma agulha de aço nos faz ser mais cuidadoso no seu manuseio do que uma agulha de madeira.

Estes foram os pontos técnicos básicos específicos da mímica do Tomaszewski com os quais construí o meu corpo poético. Uso também as divisões do corpo em cabeça, pescoço, peito, cintura, quadril e pés, que também é do Decroux, e ainda a alteração do ritmo, da velocidade, precisão no movimento, neutralidade, decupagem etc.

Mas todas estas técnicas para construir a ilusão objetiva são também usadas para construir uma subjetividade. Explico: Se uma pessoa é importante para mim, meu corpo fará o movimento convexo ao vê-la, meu corpo se moverá com muitas articulações contidas... Como já foi dito, ao segurar um revólver, independente de ser verdadeiro, de plástico ou ser feito na ilusão, além do peso, do material (se necessário for), a maneira como o utilizamos deve mostrar se este objeto dramaturgicamente vai "disparar" o problema ou se vai "resolver" o problema da história, por exemplo.

Sobre dramaturgia, além do uso da técnica já descrita para o corpo do mimo, é preciso construir também a dramaturgia no movimento. Um 
exemplo simples é o de alguém mais controlado, que se move de maneira controlada ou que, se está querendo ser objetivo, anda em linha reta; mas quando está desconfiado, no lugar de alterar algo no rosto (ou na voz, se houver), pode circundar o outro, como se o quisesse olhar mais detalhadamente, e isso será compreendido ou sentido também como desconfiança.

Além de tudo o que já foi dito, pelo qual temos pelo corpo do mimo uma dramaturgia que revela o seu personagem (ou persona), também temos a dramaturgia que revela quem é o outro personagem. Quando mostramos em cena o nosso medo pelo outro, por exemplo, estamos atribuindo ao outro uma característica complementar de violência ou poder ou... Sem que ele precise se mover. Isto é, a minha atitude propõe uma relação que, consequentemente, coloca o outro em determinado lugar. Um exemplo fácil de perceber é a entrada de um rei em cena. O rei se move sem medo e direto para onde é seu desejo, sem precisar "contar" que é poderoso. Já os demais personagens em cena fazem a reverência, se curvando, atribuindo ao rei um poder de subserviência. O poder do rei é explicitado pela ação de todos, menos do rei. $\mathrm{O}$ rei age em função do que dramaturgicamente tem que mostrar (preocupação com a guerra, felicidade pela conquista etc.).

Portanto, o mimo é um dramaturgo de si e do outro, além da situação proposta. Ele pode estar seguindo a orientação de um texto prévio ou não, com ou sem fala, mas que consegue com e pelo seu corpo fazer com que o público acompanhe esta dramaturgia pessoal, em que cada ação tem um motivo, revela algo da personagem e da situação, não necessitando de informações anteriores ou posteriores para essa mesma ação fazer sentido. Isto contempla o espectador passageiro, que assiste a um pedaço da apresentação e que sai tendo assistido a uma apresentação teatral. É o princípio do teatro de rua.

Duas questões são fundamentais para o mimo, e talvez para o artista da cena, que não são relativas à técnica, mas que são relacionadas à compreensão de sua atitude em cena. Primeiro, que o mimo "ele tem que estar em cena com a intenção de fazer sentido e não com a intenção de 
sentir. (...) Não se entra em cena buscando a emoção da personagem" (COUTINHO, 2000, p.10). Em segundo, que a dramaturgia no corpo do mimo tem por princípio propor que a plateia seja cocriadora do espetáculo. Dario Fo ao falar sobre a arte do mimo afirma que: "Não se trata de imitar literalmente as gestualidades naturais, como já observei em outras ocasiões, mas de sugerir, indicar, subentender, fazer imaginar" (FO, 2004, p.268). O mimo atua com a intenção de propor a colaboração da plateia, sugerindo, indicando, induzindo a plateia a usar a sua imaginação na construção do espetáculo.

Por isso a dramaturgia no corpo tem que ser construída para estimular a plateia a participar, contribuindo cada um com a sua imaginação. Ele deve levar para a cena um "texto" corporal incompleto, que tenha espaço para ser preenchido pela imaginação de cada um que assiste. O mimo deve entender que só no momento da relação é que a dramaturgia se completa. Há um risco inerente, já que dependemos de outra pessoa (público), que não sabemos como irá participar. Mesmo em espetáculos ensaiados! O mimo não deve estar pronto, acabado, mas preparado para o diálogo. Peter Brook fala de atores que não aceitam propostas de mudanças no dia da estreia: "Tendo construído uma estrutura definida, eles acham que, se ela for retirada, não lhes restará mais nada, ficarão perdidos" (BROOK, 1999, p.19). Isto se deve ao pressuposto de que a sua função é fazer no espetáculo exatamente aquilo que ele criou em sala de ensaio, ao invés de usar tudo o que ensaiou para, na relação, (re)criar o espetáculo a cada dia.

Todos estes princípios técnicos são alguns dos instrumentos para o mimo construir um corpo poético e consciente da sua possibilidade de criação, seja em um espetáculo improvisado, seja na criação de um espetáculo usando improvisação. Neste último, as escolhas técnicas da escrita dramatúrgica são feitas após a cena ter sido criada de improviso e não antes. $\mathrm{O}$ conhecimento técnico é fundamental para mimo ter a consciência do que ele fez e, também, para o aprimoramento da linguagem cênica. 
A mais recente constatação sobre a minha pesquisa, que foi o objeto do meu pós-doutorado, foi a de que sou um improvisador, característica de todos os atores de rua, mas que só agora inicio um estudo acadêmico buscando a minha linhagem artística histórica e contemporânea. Como já expus acima, comecei na rua, praça, passeata, festas... Depois fui trabalhar com Carlos Alberto Soffredini com a estética popular, um ator que faz personagens que narram histórias. E, por fim, hoje também atuo em Teatro de Reprise ${ }^{8}$, uma das modalidades de Teatro Espontâneo do Psicodrama. Este trajeto é o meu atual foco de pesquisa. Um ator-narrador-improvisador num corpo construído na poética do mimo.

Em 1990 me tornei professor universitário no departamento de Artes Cênicas da ECA-USP, ministrando mímica nos dois semestres do segundo ano do ciclo básico do curso em artes cênicas, bacharelado e licenciatura, portanto obrigatório para todos os alunos. Considerava as duas disciplinas como um processo único. Os conteúdos eram: trabalho de grupo (objetivando chegar à consciência de si e do coletivo), trabalho corporal (traçando um caminho da consciência corporal à técnica da mímica), e o trabalho cênico (exercitando o criar e o estar em cena a partir de improvisação). São as minhas crenças para o bom andamento de um processo teatral: conquistar a consciência de si (corporal, política, ética e em grupo), empreender a construção de um corpo poético (linguagem); e estabelecer um estado espontâneo para possibilitar, a partir da ação no improviso, o desvelar de seu discurso como artista. Moreno diz que "A espontaneidade opera no presente, isto é, agora e aqui; ela impulsiona o indivíduo na direção de uma resposta adequada a uma nova situação, ou a uma nova resposta a uma velha situação" (MORENO, 2008, p.54).

Com o tempo ficou claro que a metodologia que uso para a construção do conhecimento em sala de aula é pautada no coletivo, na corresponsabilidade de todos no processo. O meu papel de professor é, ao propor um conteúdo para a aula, principalmente orientar e estimular o

\footnotetext{
8 Mais informação, ver Rosane Rodrigues - Teatro de Reprise nas Referências. 
aluno a desenvolver o seu próprio conhecimento, seu senso crítico, com o rigor e a ética do fazer teatral.

Portanto, a minha atuação artística (criação, discurso, poética e ética), os conteúdos da minha pesquisa e a minha didática são contaminados por esta experiência, por estes valores, e têm a mesma idiossincrasia. Expõe os meus limites pessoais e as minhas paixões.

Como artista-pesquisador-professor, sou o resultado deste meu percurso, desta história vivida na carne e na imaginação. Uma busca que objetiva pensar o processo de aprendizagem, de pesquisa e de criação na e pela prática, desejando que todos também aprendam de si e com os outros, com diálogos e reflexões com os mestres práticos e teóricos, sobre a sua própria experiência, e com o prazer de estar em cena. E uma das maneiras é o processo de revisitar os nossos percursos, a partir de novos olhares, desconstruindo, mudando, reafirmando, atualizando-nos.

Com este corpo construído na poética da mímica, acredito na consciência corporal, na tentativa de observar e organizar a vida, na percepção do coletivo, no estar em diálogo constante, no se deixar levar. Este sou eu, em qualquer papel. Por vezes adequado, me ajudando a lidar com as questões que a vida propõe, por vezes, totalmente inadequado.

Não sei se as minhas afirmações pareceram respostas às minhas perguntas iniciais, talvez tenham mostrado apenas alguns caminhos escolhidos. Mas, como artista, pesquisador e professor, gostaria que servissem de provocação, que estimulasse o leitor/artista da cena a indagar, a buscar caminhos e não respostas, pois esta coerência na escrita é uma tentativa de organização de algo caótico, muitas vezes incoerente, que se organiza e se desorganiza num pulsar hesitante:

Este termo, hesitante, parece-nos fundamental. Um avanço hesitante: eis um método; avançar não em linha recta mas numa espécie de linha exaltada, que se entusiasma, que vai atrás de uma certa intensidade sentida; avanço que não tem já um trajecto definido, mas sim um trajecto pressentido, trajecto que constantemente é posto em causa; quem avança hesita porque não quer saber o sítio para onde vai - se o soubesse já, para que caminharia ele? Que pode ainda descobrir quem conhece já o destino? Hesitar é um efeito da ação de descobrir; só não hesita quem já descobriu, quem já colocou um ponto final no seu processo de investigação (TAVARES, 2013, p.26). 


\section{REFERÊNCIAS}

BROOK, Peter. A porta aberta. Rio de Janeiro: Civilização Brasileira, 1999.

BURNIER, Luís Otávio. A arte do ator: da técnica à representação. Campinas, SP: Ed. Unicamp, 2009.

COUTINHO, Eduardo Tessari. O mimo e a mímica: Uma contribuição para a formação do ator brasileiro. 1993. 123. Dissertação Programa em Artes ECA-USP, São Paulo, 1993.

COUTINHO, Eduardo Tessari. Uma Cena Precisa: Procedimentos para uma cena quase pronta. 2000. 219. São Paulo, Tese Programa em Artes ECA-USP, São Paulo, 2000.

FO, Dario. Manual Mínimo do Ator. São Paulo: Ed. Senac, 2004.

MORENO, Jacob L. Quem sobreviverá? Fundamentos da sociometria, da psicoterapia de grupo e do sociodrama. Edição do estudante. São Paulo: Daimon, 2008.

REY, Alain. Aucoeurdu mime, lamiméses. In: LECOQ, Jacques (org.). Le théâtredu geste. Mime et acteurs. Paris (França): Bordas, 1987. p. 11-13.

RODRIGUES, Rosane. Teatro de Reprise: Improvisando com e para grupos. São Paulo: Ágora, 2016.

TAVARES, Gonçalo M. Atlas do Corpo e da Imaginação. Alfragide (Portugal): Editorial Caminho, 2013.

Recebido em março de 2019.

Aprovado em abril de 2019.

Publicado em junho de 2019. 